\title{
INVESTIGATION INTO THE APPLICATION OF MULTIPLE CRITERIA DECISION MAKING FOR AN ONLINE CANDIDATE SHORT LISTING SYSTEM
}

\author{
Pathiranage Padmali Manesha Peiris* \\ School of Computing \\ Asia Pacific Institute of Information Technology \\ Colombo, Sri Lanka \\ Email:manesha@apiit.lk \\ Mr. Syed Rehan \\ School of Computing \\ Asia Pacific Institute of Information Technology \\ Colombo, Sri Lanka \\ Email: rehan@apiit.lk \\ Dr. Gayan Jayakody \\ School of Computing \\ Asia Pacific Institute of Information Technology \\ Colombo, Sri Lanka \\ Email: gayan@apiit.lk
}

\begin{abstract}
The process of screening candidates is a common operation carried out by organizations in areas such as recruitment, selection of candidates for university admittance, awarding of scholarships etc. The selection process in the area of awarding scholarships often uses a manual framework which examines the candidate's qualifications according to that specified by the donor country. The main objective of this research paper is to eliminate the core inefficiencies faced within this framework, thus improving the quality of the final decision by facilitating the selection of the most deserving candidate and minimizing the degree of personal preference. In order to perform this task, the following document considers four Multiple Criteria Decision Making Models (MCDM) techniques namely Simple Additive Weighting Model (SAW), Multiplicative Exponential Weighting Model (MEW), Technique for Order Preference by Similarity to Ideal Solution (TOPSIS) and Analytical Hierarchy Process (AHP). The proposed solution integrates SAW and AHP to shortlist the applications received via a web application which acts as an interface between the applicants and selection panel. AHP was used to develop a weight-age model which utilizes pair-wise comparison to identify the relative importance of each criteria used to evaluate candidates. Furthermore SAW was used to develop a score for each candidate according to their qualifications and the weight assigned by AHP. As a result of the proposed framework the throughput efficiency of the overall short listing procedure was proven to be improved by $30.14 \%$, eliminate the need for manual labor by $80 \%$ and speed up time by $70 \%$.
\end{abstract}

Keywords: Decision Support System (DSS), Analytical Hierarchy Process (AHP), Simple Additive Weighted Model (SAW), Short Listing 


\section{Introduction}

For developing countries such as Sri Lanka scholarships are essential to provide access to higher education for the large segment of the population which qualify for higher education but cannot be accommodated within the local university system due to the sheer capacity and lack of facilities. All scholarships are received by a central organization and a study revealed that these scholarships are received at an annual basis. Once the scholarships are received the organization must work within a tight schedule to call in applications and shortlist these candidates for interviews in order to make the final selection. Due to the time lags in between each stage in the process the organization is often faced with situations where the selection is delayed beyond the deadline assigned by the donor country. The task of short listing is conducted manually within the organization and consumes a lot of resources which results in unnecessary expenses to the organization. Due to the manual selection process a certain degree of personal preference is introduced into the process regardless of the criteria followed. This has resulted in a high degree of dissatisfaction from the general public towards the process.

Based on the findings given above the process of candidate short listing was studied and a model was constructed for the organization according to the model proposed by Fisher et al. (2003) as illustrated in Figure 1.

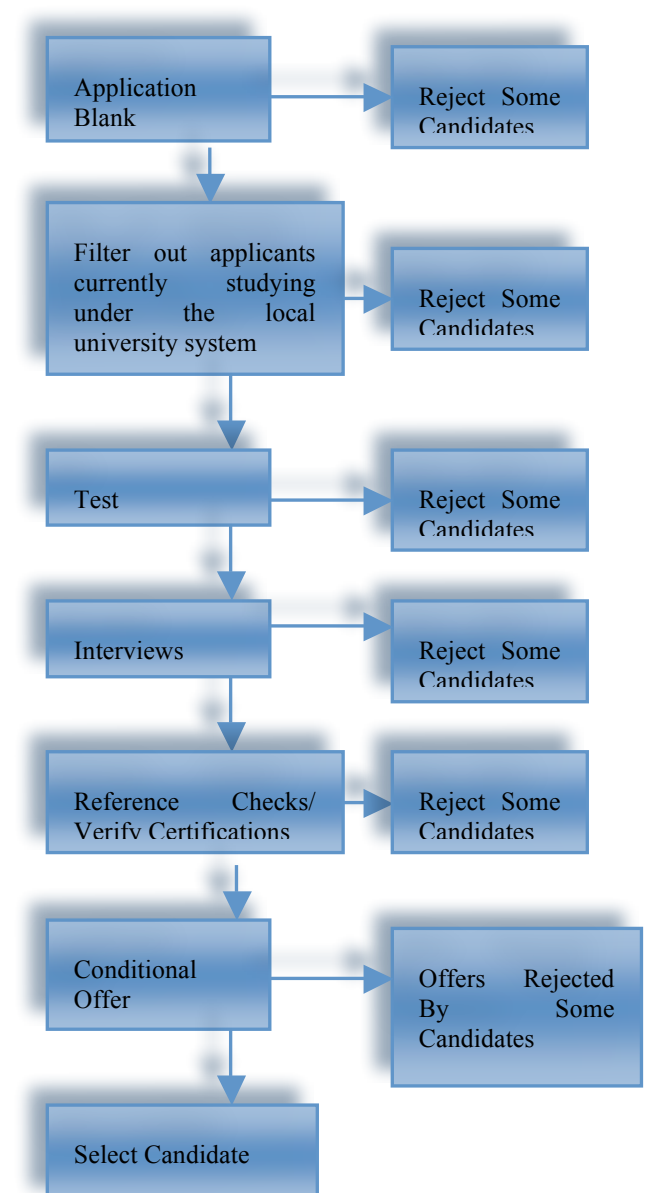

Figure 0: Short Listing Process

When considering the area of personnel selection, the application of new technologies such as expert system and decision support systems are increasingly becoming popular and gaining momentum among companies (Beckers \& Bsat, 2002; Kovach \& Cathcart, 1999; Liao, 2003 cited by Chien \& Chen, 2006). Thus such technologies can be utilized in order to overcome the inefficiencies in the process of candidate 
selection for scholarships. Furthermore Models such as AHP play a vital role in reducing the subjectivity of the decision making process, and when linked with automation can help eliminate unnecessary steps in the overall process.

\section{Problem Statement}

The main Problem statement for the following research paper can be mentioned as:

"What technique can be incorporated to improve the quality of the ultimate candidate selection whilst reducing the amount of time spent on the selection process as well as the degree of personal preference and subjectivity in the final selection?"

\section{The decision making process}

Decision making is a human cognitive process in which various alternatives, actions and events are evaluated to come to conclusive outcome. According Pomerol \& Adam (2003) the human decision making process can be divided into three sections namely; diagnosis, look-ahead and outcome set as illustrated in Figure 2.

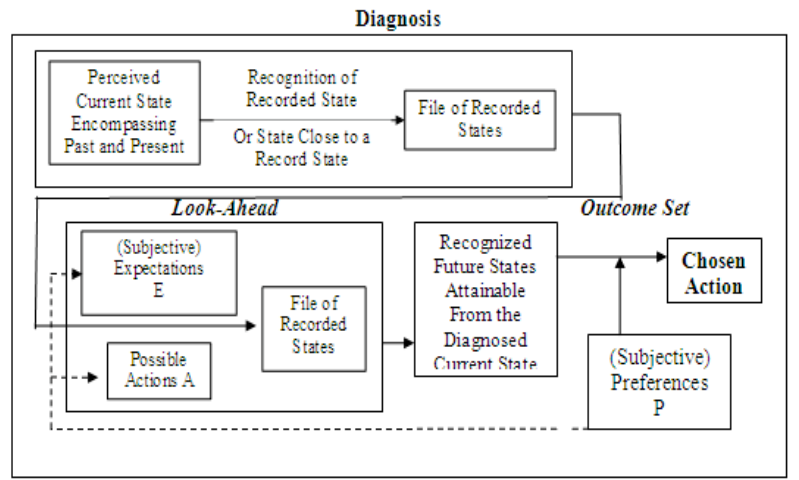

Figure 0: Human decision making Process

(Pomerolm \& Adam 2003)

In the diagnosis section the decision maker identifies and assesses the situation at hand. Once this information is identified, the individual will assess the expected results as well as the various alternatives available. Based on the outcome of the look-ahead process the individual will come to a set of results. When applying this to the scenario related with candidate selection for scholarships which was discussed in Figure 1, the decision makers will first identify the current situation at hand, for example the number of scholarships available, their requirements, the procedures which were previously carried out in similar situations and the criteria which must be followed in order to achieve the desired goal as well as statistical information regarding students who have qualified but not gained entrance into local universities. Once this is identified there is a need to look at the set of actions which need to be taken to achieve the final goal such as evaluation and screening of applicants. This together with the decision maker's preferences will lead to the final decision or choice, which would be the most suitable candidates to be awarded undergraduate scholarships.

This consecutively introduces a high degree of personal preference in to the overall selection process since the screening process as well as the prioritization of the selection criteria is based completely on human judgment. A solution to overcome the inefficiencies faced can be application of DSS technologies 
to support the decision making process within the sequence of steps specified previously. The following research paper discusses the application of an online DSS framework which will enable the following benefits to the organization:

- Enable applicants to apply for scholarships online thus eliminating the use of records in physical paper format.

- Speed up the application screening procedure since all applications will be in

\section{Literature Review}

Today the need for more efficient decision support has become critical, independent of the management level it is applied to. To facilitate accurate decision making various applications are continuously being introduced to the market. We commonly hear the terms Decision Support System (DSS), Data Warehousing, Online Analytical Processing (OLAP) and Expert System (ES) when discussing decision support. But they are only a handful of the applications available today to serve the process of decision making, when discussing Decision Making Support Systems there is primarily a need to identify the structure of the DSS as well as the type of DSS which is best suited to the scenario under consideration. The following section will discuss the various Multiple Criteria Decision Making (MCDM) Techniques which can be applied to the scenario at hand.

\subsection{DSS Frameworks}

The selection of a suitable decision support technology must be made with great care, taking into consideration and nature of the decision making process and the attributed which are required.

A study carried out by Forgionne (2000 cited by Pomerol \& Adam 2003) state that there is a need to develop information systems which support the decision making needs of an organization. By collaborating with Simons four phase paradigm of intelligence (1960 cited by Pomerol \& Adam 2003) a set of procedures within the decision making process has been identified as illustrated in Figure 3. 


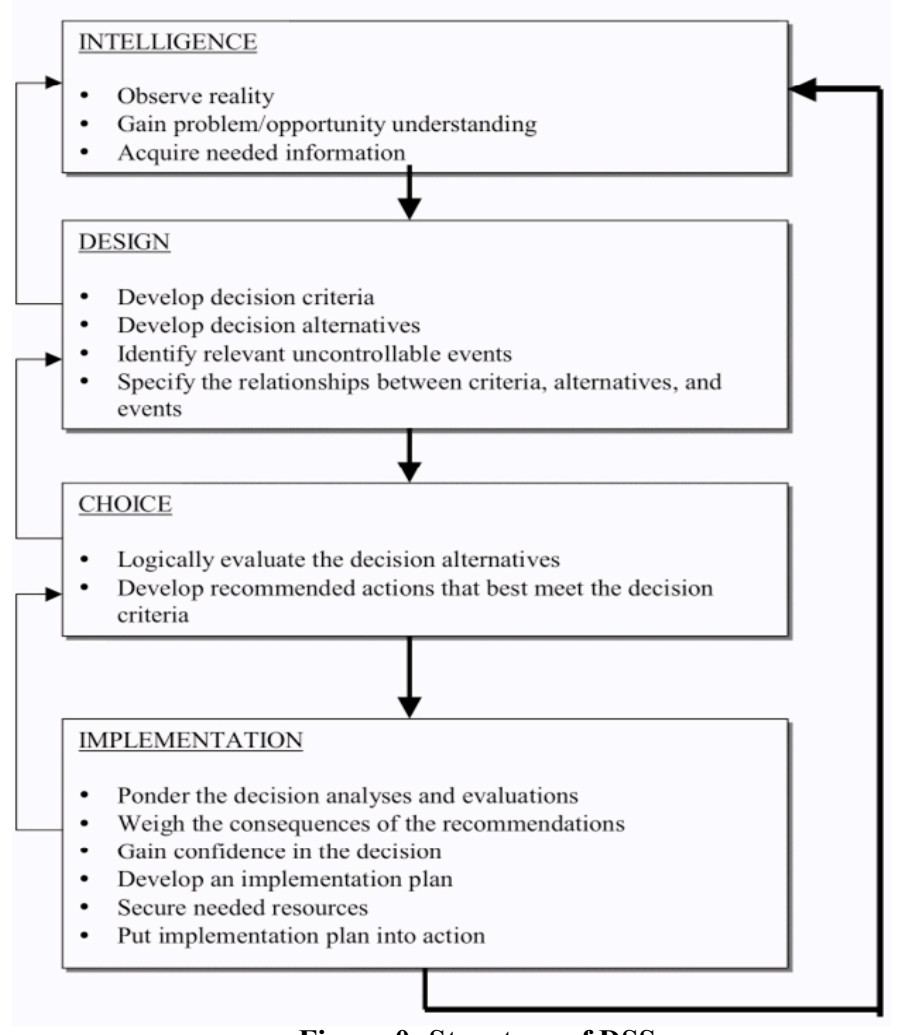

Figure 0: Structure of DSS

(Pomerolm \& Adam 2003)

Based on this model an investigation was conducted to identify the most suitable DSS dichotomy which will overcome the fundamental flaw in DSS applications, as identified by Simon (cited by Pomerol \& Adam, 2004) the model represents a high degree of dependency in the previous stages in order to come up with an accurate result. This flaw is further facilitated by the fact that often little attention is given to the information fed into the system. Thus the proposed system must be one which looks at the underlying architecture as well as the quality of the inputs required.

On consideration of the various models available for decision

making it was identified that the proposed solution must incorporate a Model Driven DSS due to the fact that the outcome of the decision making process is highly dependent on the models utilized for the selection and filtering of potential candidates.

\subsection{Existing Decision Models for Selection}

On investigation of the subject area it was identified that a number of research papers have been dedicated to the identification of selection models in various application areas. Eldrandaly, Eldin and Sui (2003) discuss the successful application of a decision support system for industrial site selection using multiple criteria decision making, more specifically AHP. In this research AHP plays an important role in the evaluation of the sites combined with Geographic Information Systems (GIS) and Expert System (ES) Technologies. Schafer (2001) discuss the usage of Multi-Attribute Utility Theory (MAUT) in organizations such as German Company "Stiftung Warentest" for product evaluation. Chou, Chang \& 
Shen (2007) further discuss the usage of Simple Additive Weight age model for facility location design in the area of supply chain design. Based on these researches it was identified that the most commonly utilized solutions are Multiple Criteria Decision Making (MCDM) models.

\subsection{Methodology investigation}

Stutzke (2007) discuss two major categories of models used for multiple criteria decision making. These models are also referred to as normative models. Normative models are those, in which all alternatives are compared in order to distinguish the best alternative (Turban, Aronson \& Liang, 2005).

These models are; expected utility theory and multi-attribute utility theory (Stutzke, 2007). According to the expected theory the value of a particular outcome is determined by the probability of occurrence multiplied by the utility of that outcome. The multi attribute utility theory (MAUT) is an extension of the expected theory to accommodate multiple attributes (Stutzke, 2007). As stated previously the main focus of this research will be on models which support Multiple Criteria Decision Making.

Al-Najjar and Alsyouf (2002) further provide three types of models used for multiple criteria decision making: Simple Additive Weighting (SAW), Multiplicative Exponential Weighting (MEW), and Technique for Order Preference by Similarity to Ideal Solution (TOPSIS) and Analytical Hierarchy Process (AHP). The following section will evaluate each model in order to identify the most suitable model to be applied to the solution.

To test the accuracy of each model the following scenario was applied:

In the case of scholarship candidate selection, several attributes can be identified such as; Z-Score value, extracurricular activities, other certifications and each attribute were assigned a weight of 6,4 and 2 respectively. Let us assume that the marks awarded for each student for each attribute was as follows, (assume that all marks were awarded on a scale of 1-10)

Table 1: Student Marks

\begin{tabular}{|l|l|l|l|}
\hline Student & Z-Score & $\begin{array}{l}\text { Extra curricular } \\
\text { activities }\end{array}$ & $\begin{array}{l}\text { Other } \\
\text { certifications }\end{array}$ \\
\hline 1 & 8 & 3 & 1 \\
\hline 2 & 5 & 8 & 1 \\
\hline 3 & 4 & 5 & 5 \\
\hline 4 & 6 & 1 & 2 \\
\hline
\end{tabular}

The candidates will be referred to as S1, S2, respectively in the following sections.

\subsubsection{Application of the Simple Additive Weight age (SAW) Model}

Also known as weighted linear combination or scoring method. The following equation was used in order to calculate the results:

$$
V_{i}=\sum_{j=1}^{n} w_{j} r_{i j} \quad i=1,2,3, \ldots, n
$$

(Chang and Yeh, 2001) 
The SAW values for each student will be:

$$
\begin{array}{ll}
\mathrm{S} 1=62 & \mathrm{~S} 2=64 \\
\mathrm{~S} 3=54 & \mathrm{~S} 4=44
\end{array}
$$

Based on the results Student 2 (S2) would be the most suitable candidate. But it must be noted that the Zscore is given priority. Thus the question must be asked, why Student 1(S1) was not selected since he has the highest Z-score. Therefore it can be said that this technique would not be effective when selecting candidates to be awarded scholarships.

\subsubsection{Application of the Multiplicative Exponential Weight age (MEW) Model}

Also known as Weighted Product Method (WP) it is a MADM (Multiple Attribute Decision Making) scoring method. The following equation was used in order to calculate the results:

$$
\begin{gathered}
\sum_{I=1}^{N} w_{j}=1 \\
S_{i}=\prod_{j=1}^{n} x_{i j}^{w j}
\end{gathered}
$$

(Chang and Yeh 2001)

For easier comparison with other methods Chang and Yeh (2001) have developed an additional formula which can be represented as:

$$
\mathrm{V}_{\mathrm{i}}=\frac{\Pi_{j=1}^{n} x_{i j}^{w j}}{\Pi_{j=1}^{n}\left(x_{j}^{*}\right)^{w j}}, \mathrm{i}=1,2,3, \ldots, \mathrm{n}
$$

(Chang and Yeh 2001)

On application the following results were obtained:

$$
\begin{array}{ll}
\mathrm{S}_{1}=21,233,664 & \mathrm{~V}_{1}=0.0079 \\
\mathrm{~S}_{2}=64 & \mathrm{~V}_{2}=0.00238 \\
\mathrm{~S}_{3}=64 & \mathrm{~V}_{3}=0.00238 \\
\mathrm{~S}_{4}=186,624 & \mathrm{~V}_{4}=0.00000695
\end{array}
$$

Based on these results it can be said that the most preferred alternative is candidate No. 1. In this example it is clearly evident that even though Students 2 and 3 have gotten different results for each attribute considered, both were given the same overall ranking. Therefore it is evident that this technique is less sensitive to slight variations. In the context of selecting applicants to be granted scholarships there is a need to critically evaluate each applicant relative to each other. This equation fails to meet the needs of the ministry when selecting candidates. Therefore it can be said that this technique would not be effective when selecting candidates to be awarded scholarships.

\subsubsection{Application of the Technique for Order Preference by Similarity to Ideal Solution (TOPSIS)Model}

In this technique the best candidate solution is the one which is closest to the ideal solution. As defined by Chang and Yeh (2001) the preferred alternative must have the shortest distance from the positive ideal solution while having the longest distance from the worst solution or the negative ideal solution. 
The normalization of values can be carried out by:

$$
r_{i j}=\frac{x_{i j}}{\sqrt{\sum_{i=1}^{m} x_{i j}^{2}}}, \quad i=1,2, \ldots, m, j=1,2, \ldots, n
$$

(Chang and Yeh 2001)

$\mathrm{r}_{\mathrm{ij}}$ denotes the normalized performance rate and $\mathrm{x}_{\mathrm{ij}}$ denote attribute $\mathrm{j}$ of candidate $\mathrm{i}$.

The ideal solution (A) must be calculated as:

$Z_{i j}=w_{j} r_{i j}, i=1,2, \ldots, m, j=1,2, \ldots, n$,

$\mathrm{A}^{+}=\left(\mathrm{z}_{1}^{+}, \mathrm{z}_{2}^{+}, \ldots, \mathrm{z}_{\mathrm{n}}^{+}\right), \mathrm{A}^{-}=\left(\mathrm{z}_{1}^{-}, \mathrm{z}_{2}^{-}, \ldots, \mathrm{z}_{\mathrm{n}}^{-}\right)$

Where

$$
Z_{j}^{+}\left\{\begin{array} { l } 
{ \operatorname { M a x } _ { i } z _ { i j } \text { if } j \text { is a benefit attribute, } } \\
{ \operatorname { M i n } _ { i } z _ { i j } \text { if } j \text { is a cost attribute } }
\end{array} \quad Z _ { j } ^ { - } \left\{\begin{array}{l}
\operatorname{Max}_{i} z_{i j} \text { if } j \text { is a benefit attribute, } \\
\operatorname{Min}_{\mathrm{i}} z_{i j} \text { if } j \text { is a cost attribute } \\
j=1,2, \ldots, n
\end{array}\right.\right.
$$

(Chang and Yeh, 2001)

Based on the formulas given above, the calculation of the positive ideal solution:

Let us assume that the desired value for each alternative is as follows;

Table 2: Positive Ideal Solution

\begin{tabular}{|c|c|c|}
\hline Z-Score & Extra Curricular Activities & Other Certifications \\
\hline 8 & 7 & 5 \\
\hline
\end{tabular}

Then, $Z_{1}=48 \quad Z_{2}=28 \quad Z_{3}=10$

Calculation of the negative ideal solution:

Let us assume that the desired value for each alternative is as follows;

Table 3: Negative Ideal Solution

\begin{tabular}{|c|c|c|}
\hline Z-Score & Extra Curricular Activities & Other Certifications \\
\hline 5 & 5 & 1 \\
\hline
\end{tabular}

Then, $Z_{1}=30 \quad Z_{2}=20 \quad Z_{3}=2$

Distance between each alternative and the positive preferred solution:

$\mathrm{D}_{1}+=17.9 \quad \mathrm{D}_{2}+=20.1 \quad \mathrm{D}_{3}+=25.3 \quad \mathrm{D} 4+=27.49$

Distance between each alternative and the negative preferred solution:

$\mathrm{D}_{1^{-}}=19.7 \quad \mathrm{D}_{2^{-}}=12 \quad \mathrm{D}_{3^{-}}=10 \quad \mathrm{D}_{4^{-}}=17.2$

Overall preferred value:

$\mathrm{V}_{1}=0.52 \quad \mathrm{~V}_{2}=0.37 \quad \mathrm{~V}_{3}=0.28 \quad \mathrm{~V}_{4}=0.38$

Based on these results it can be said that the candidate No. 1 would be the most preferred candidate. By calculating the distance between each alternative and the negative and positive preferred solution, a much clearer evaluation can be carried out. The equation considers the relative preference of each alternative, thus providing an overall ranking to each candidate relative to each other. 


\subsubsection{Application of Analytical Hierarchy Process (AHP)}

As stated by Saaty (1980 cited Leung \& Cao, 2000) AHP provides a frame work for making multi attribute decisions. One of the core competencies of AHP can be considered to be the degree of attention given to pair wise comparison of the criterion in order to establish weights. Pair wise comparison $\mathrm{s}$ discussed by Gass (1998) is a framework which allows you to rank items in relation to each product. To do this, AHP utilizes a grid as shown below.

But as discussed by Mamat $\&$ Daniel (2003) as the number of alternatives increase the evaluation of these alternatives using Pair Wise comparison will become more difficult. When considering the sheer number of applicants received by the organization (estimated total number of scholarship applications received each year is 16,000 to 20,000) AHP will not be applicable to carry out pair wise comparison of each applicant, thus AHP was utilized for the identification of the weights to be assigned for each criteria.

\subsubsection{Selection of Analytical Hierarchy Process (AHP) Model}

Given below is a table specifying the Pair Wise comparison values created for a scale of 1-9.

Table 4: Pair wise comparison scale

\begin{tabular}{|l|l|}
\hline Comparison description & Value \\
\hline Extremely more important & 9 \\
\hline Very Strongly important & 7 \\
\hline Strongly important & 5 \\
\hline Moderately more importance & 3 \\
\hline Of equal importance & 1 \\
\hline Moderately less important & $1 / 3$ \\
\hline Weakly important & $1 / 5$ \\
\hline Very weakly important & $1 / 7$ \\
\hline Extremely less important & $1 / 9$ \\
\hline
\end{tabular}

Thus the previously specified criteria can be evaluated using the scale as follows. It must be noted that the evaluator(s) must fill each box by critically accessing each alternative with the other. For example the evaluator must ask themselves: what is the relationship between extracurricular activities and the Zscore? What is more important? To what degree is it important? Then inserting these values one can fill in the comparative values for one section (highlighted section) and use the inverted values for the other section.

Let us consider the example considered in the previous sections. Here the criteria used to evaluate an alternative can be further specified as: Z-Score, Extracurricular activities, other certifications, O/L results and Island ranking. The following looks at the application of AHP in to the scenario.

Table 5: Application of Reciprocity Rule

\begin{tabular}{|l|l|l|l|l|l|}
\hline & Z-Score & $\begin{array}{l}\text { Extra } \\
\text { Curricular } \\
\text { Activities }\end{array}$ & $\begin{array}{l}\text { Other } \\
\text { certifications }\end{array}$ & O/L results & $\begin{array}{l}\text { A/L Island } \\
\text { Ranking }\end{array}$ \\
\hline ZrScore & 1.000 & 9.000 & 9.000 & 7.000 & 3.000 \\
\hline Extra Curricular Activities & 0.111 & 1.000 & 1.000 & 1.000 & 0.200 \\
\hline Other certifications & 0.111 & 1.000 & 1.000 & 1.000 & 0.140 \\
\hline O/L results & 0.143 & 1.000 & 1.000 & 1.000 & 0.200 \\
\hline A/L Island Ranking & 0.333 & 5.000 & 7.143 & 5.000 & 1.000 \\
\hline
\end{tabular}

On conducting the necessary calculations the average of all the values obtained will be calculated (row wise). This will be the final weight age of each criterion. 
Table 6: Calculated Weights

\begin{tabular}{|l|l|}
\hline Criteria & Average Weight \\
\hline Z-Score & 0.543161 \\
\hline Extra Curricular Activities & 0.05744 \\
\hline Other certifications & 0.054797 \\
\hline O/L results & 0.061179 \\
\hline A/L Island Ranking & 0.283422 \\
\hline
\end{tabular}

To eliminate the possibility of personal preference and biasness in the final decision, a consistency ration and consistency index must be calculated (Teknomo, 2006). The calculation of the consistency ratio was carried out the following results was obtained:

Table 7: Consistency Vector Calculation

\begin{tabular}{|l|l|l|l|}
\hline Criteria & Total & Total / Average Weight & Calculated Value \\
\hline Z-Score & 2.8318 & $2.8318 / 0.543161$ & 5.2136 \\
\hline Extra Curricular Activities & 0.2905 & $0.2905 / 0.05744$ & 5.0566 \\
\hline Other certifications & 0.2734 & $0.2734 / 0.054797$ & 4.9902 \\
\hline O/L results & 0.3077 & $0.3077 / 0.061179$ & 5.0294 \\
\hline A/L Island Ranking & 1.4490 & $1.4490 / 0.283422$ & 5.1124 \\
\hline
\end{tabular}

Eigen Value $\left(\lambda_{\max }\right) \quad=5.080443$

Consistency Index $(\mathrm{CI}) \quad=\underline{\left(\lambda_{\max }-\mathrm{n}\right)} \quad=0.02011$

$(\mathrm{n}-1)$

By utilizing the Scale developed by Saaty (1980 cited Teknomo, 2006) for accessing the Random Consistency Index the Random Index can be calculated.

Consistency Ratio (CR) $\quad=\frac{\text { Consistency Index }(\mathrm{CI})}{\text { Random Index (RI) }}=0.017$

According to Saaty (1980 cited Teknomo, 2006) if the CR value is less than $0.1(10 \%)$ then the inconsistency is acceptable. Else there is a need to revise the comparative values assigned to each criterion. In the previous example the $\mathrm{CR}<0.1$ thus there is a low degree of biasness in the competitive values assigned. Thus the weights calculated are acceptable.

From the above analysis it was evident that by using AHP the evaluators will be able to come to a more accurate unbiased result. But it was identified that the identification of necessary unbiased comparative values for each criterion is a cumbersome process, an inconsistency in the comparison matrix would result in biasness in the entire decision making process. A proposed solution for this issue will be discussed in the next section.

\subsubsection{Critical Evaluation of Decision Making Models}

Based on the evaluation carried out previously, it was identified that weighting models and AHP are both decision making models which are commonly used for alternative selection. But form these techniques only one qualifies as the most suitable to be applied to the context of scholarship candidate selection. The 
following evaluation will identify the most suitable hybrid to be applied to the scenario under consideration.

Three types of weighting models where identified and evaluated, as a result several factors where revealed based on the application of each equation:

When comparing the results obtained it was identified that the MEW is less sensitive to slight changes in the scores awarded to each candidate, resulting in two candidates having drastically different scores being awarded the same ranking. Due to this reason this model can be eliminated from the list of choice.

When comparing SAW and TOPSIS, it can be said that theoretically TOPSIS is more robust than SAW because it consider the alternative in regarded to the most desirable result by considering the distance of each result from the most desirable and the least desirable result. This would further increase the accuracy of the final result. Thus TOPSIS can be said to be a much stronger weighing model when compared with MEW and SAW.

Furthermore Shih et al. (2006) state that TOPSIS provides the following benefits:

- A sound logic that represent the rational of human resource

- A scalar value that account for both the best and worst alternatives simultaneously

- A simple computation process that can be easily programmed into a spreadsheet

- The performance measure of all alternatives on attribute can be visualized on a polyhedron

Shih et al. (2006) also states that due to the advantages stated above TOPSIS is a major MADM technique when compared to AHP. TOPSIS is considered as one of the major decision making techniques used in the Asia Pacific area for human resource management, transpiration, product design, and etcetera.

But on the other hand it must also be noted that the identification of the ideal candidate for the TOPSIS calculation is entirely subjective, thus introducing biasness to the overall result. The main purpose of this project is to reduce the overall bias in candidate selection and to speed up the process. Taking these factors into consideration SAW was selected as the preferred weighted model. Zanakis et al (1998 cited Chou, Chang \& Shen, 2008) discusses the evaluation of eight MADM methods, based on this investigation it was concluded that SAW performed better than MEW, TOPSIS and AHP. Furthermore Chang and Yeh (2001 cited Chou, Chang \& Shen, 2008) discuss the superiority of SAW in an empirical study of SAW, weighted product and TOPSIS. In conclusion Chou, Chang \& Shen (2008) state a simpler evaluation technique is often superior to other complex techniques.

A major disadvantage of SAW can be explained as the establishment of the weights is subjective. As discussed in the next section, this can be overcome by adapting AHP to establish the weights as illustrated in Figure 4. 


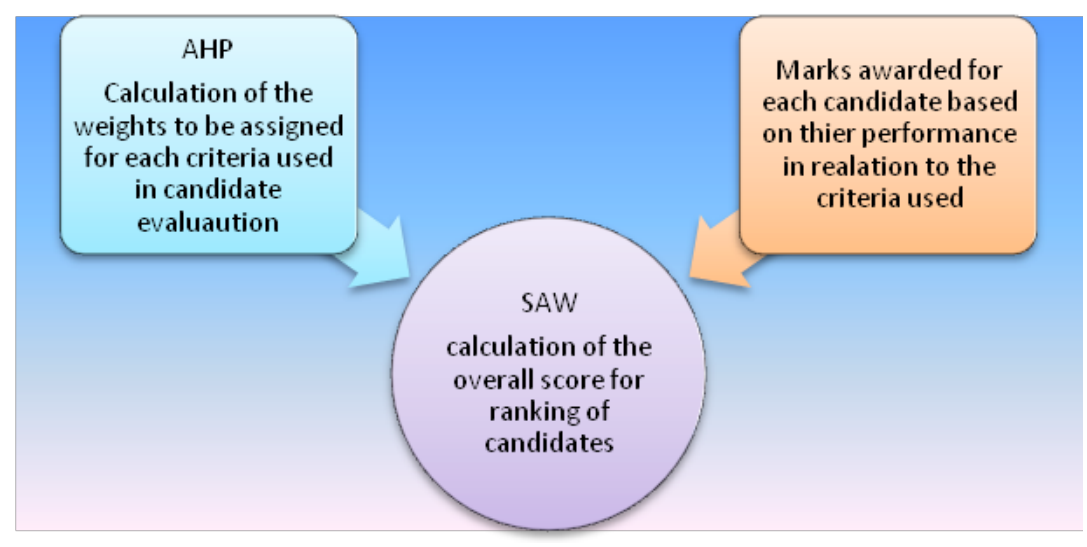

Figure 1: Combined Model

When considering the discussion in part 3.3.4 the proposed system will incorporate the Consistency Index (CI) to identify the level of biasness within the selections made, if such biasness is evident the user will be requested to re-select. This will facilitate the minimization of the degree of biasness in the selection.

\section{Application of the selected model in Candidate selection}

Based on the findings a model was proposed as follows which utilizes AHP for determination of the weights to be assigned to the criteria which are then combined with SAW to calculate the overall score. The candidates are then ranked based on the calculations carried out. The following illustration portrays the overall process which is conducted in order to make the candidate selection for a scholarship. 


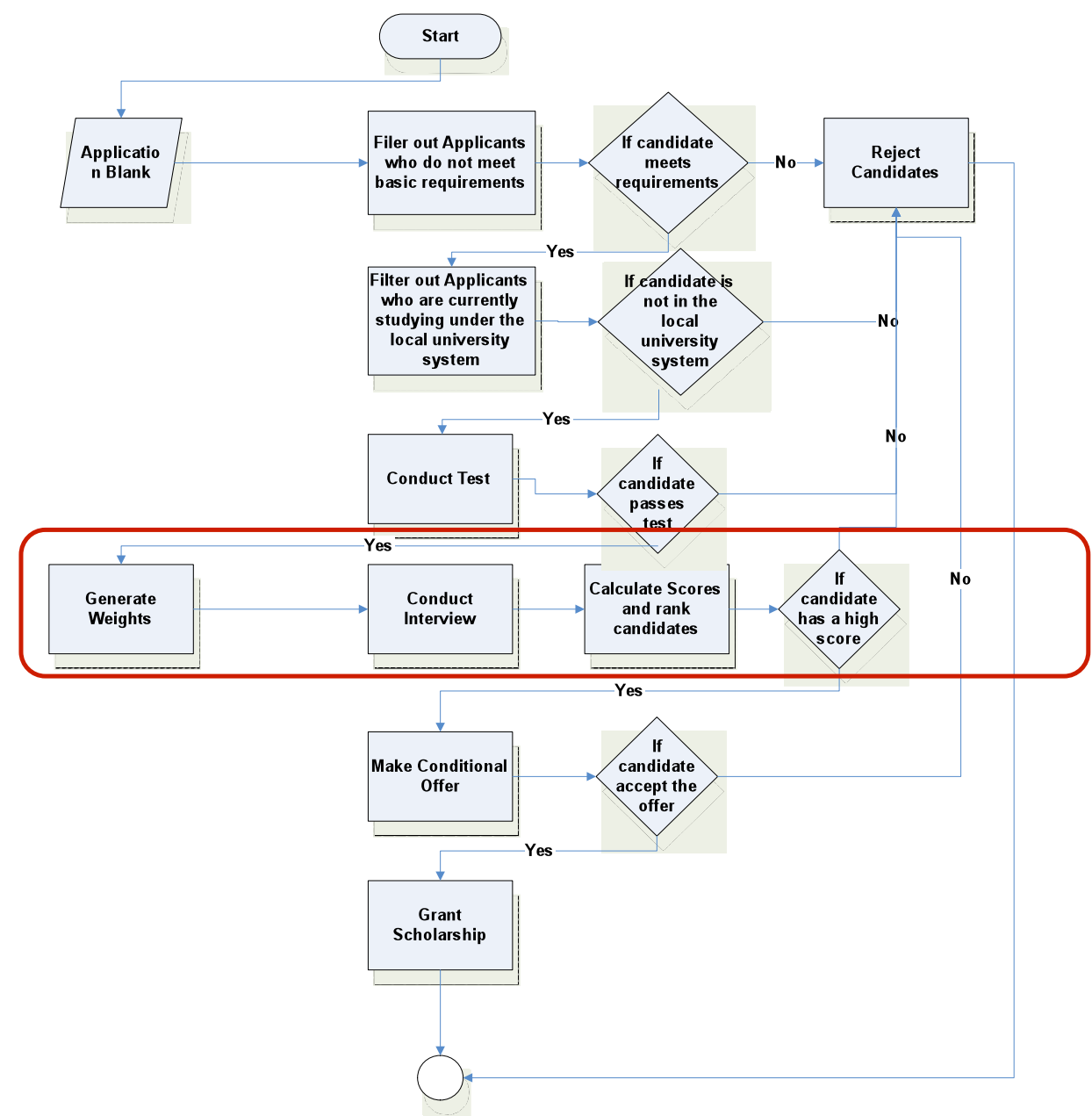

Figure 2: Overall Application Structure

The area highlighted indicates the component carried out by the application. Let us now focus more on the weight generation and score calculation component of the application. This can be illustrated as follows:

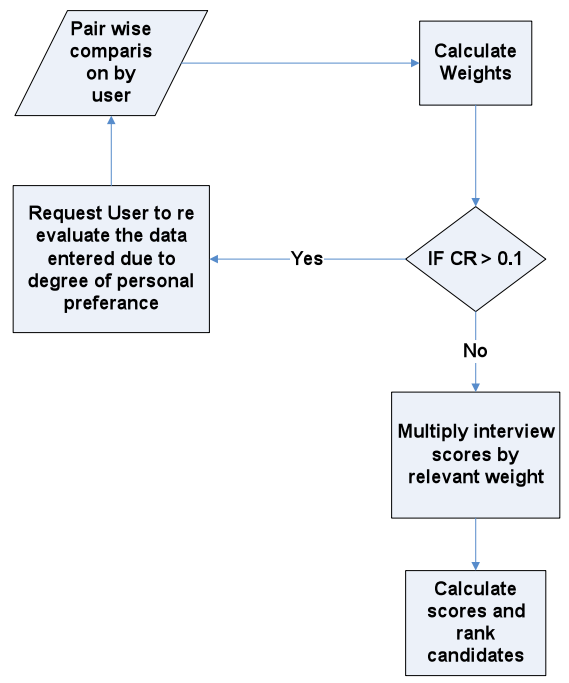

Figure 3: Weight age Calculation Model 
In order to better explain the application of the model, an example was used as follows. Let us assume that the following marks were awarded to 4 students under the five criteria's discussed in the 4.3.4. The marks awarded to the students $1-4$ are listed in the table below: (assume that all marks were awarded on a scale of 1-10).

Table 8: Student Marks Table

\begin{tabular}{|l|l|l|l|l|l|}
\hline & Z-Score & $\begin{array}{l}\text { Extra Curricular } \\
\text { Activities }\end{array}$ & $\begin{array}{l}\text { Other } \\
\text { certifications }\end{array}$ & O/L results & A/L Island Ranking \\
\hline $\mathbf{1}$ & 8 & 3 & 1 & 3 & 7 \\
\hline $\mathbf{2}$ & 5 & 8 & 1 & 5 & 1 \\
\hline $\mathbf{3}$ & 4 & 5 & 5 & 9 & 4 \\
\hline $\mathbf{4}$ & 6 & 1 & 2 & 2 & 4 \\
\hline
\end{tabular}

Initially the weights will be calculated based on the level of importance of each criterion. For this purpose let us utilize the weights developed in the previous example in part 4.3.4.

Table 9: Weight age for each Criterion

\begin{tabular}{|l|l|}
\hline Criteria & Average Weight \\
\hline Z-Score & 0.543161 \\
\hline Extra Curricular Activities & 0.05744 \\
\hline Other certifications & 0.054797 \\
\hline O/L results & 0.061179 \\
\hline A/L Island Ranking & 0.283422 \\
\hline
\end{tabular}

Using the SAW model selected previously, calculations will be done to develop scores for each candidate.

$\mathrm{S} 1=7.233069 \quad \mathrm{~S} 2=4.312612 \quad \mathrm{~S} 3=6.883993 \quad \mathrm{~S} 4=5.668392$

According to this calculation it can be said that the candidates can be ranked in descending order according to their overall score as:

S1 having a score of 7.233069

S3 having a score of 6.883993

S4 having a score of 5.668392

S2 having a score of 4.312612

\section{Implementation}

The solution formulated is a web based candidate selection system. From the candidate's point of view, it will enable them to search for and apply for scholarships. These scholarships can be filtered according to the user's requirements or based on the scholarships which are most suited for their qualifications. From the decision makers perspective it will enable them to state the degree of importance of each selection criterion in order to shortlist the most suitable set of candidates. The following illustration depicts the main makeup of the proposed solution.

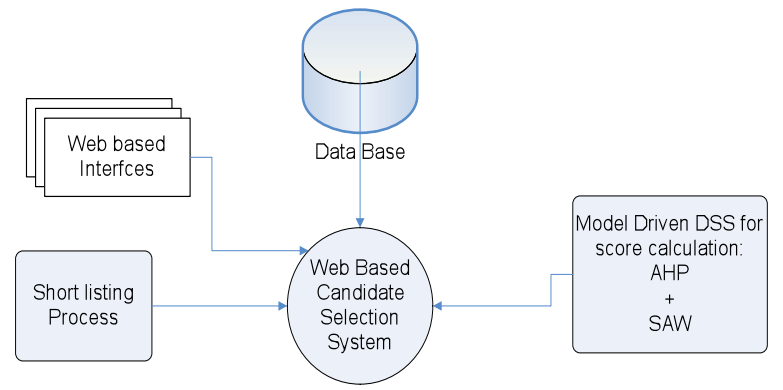

Figure 4: System Framework 
The proposed model consists of 3 components as shown in the above diagram; the database component will be the main storage location of the data required for the underlying model and the candidate selection process. The users will interact with the system using a web based interface which has been designed taking usability principles into consideration. The candidate selection is enabled by two components: the short listing process which will focus on the preliminary elimination of unsuitable candidates based on their basic qualifications, and the Model Driven DSS which will utilize the selected Multiple Criteria Decision making Models discussed earlier.

\section{Discussion}

Based on the findings of the above research paper several outcomes were identified. The system which utilized two underlying models to improve the overall efficiency of the selection was implemented in the organization. It was observed that the system was able to cut the costs incurred in the process by $87 \%$ and the time span from weeks to days. The number of applications also proved to increase by $40 \%$ proving the web application now proved to be more accessible to the candidates. In order to test the accuracy of the selection the system was tested in parallel by incorporating a Delphi method which allowed the selection panel to evaluate candidates and make the selection. The process was evaluated through several iterations and the system proved to be accurate in each. Therefore it was acknowledged that the model combining SAW and AHP was successfully implemented into the scenario.

\section{Conclusion}

As the need for more efficient decision making becomes vital for organizations, Decision Support Systems are increasingly becoming a popular solution. Based on the research conducted it was identified that the most suitable solution utilized a model driven frame work. But on further investigation it was revealed that a weight age model alone was insufficient due to the amount of personal preference which would be introduced in to the selection process, causing it to be very subjective. Thus AHP was used to minimize the degree of subjectivity in the overall selection, enabling pair wise comparisons of each selection criterion. AHP is a powerful tool for eliminating the errors in human subjective thinking.

Based on the investigation it was identified that though AHP has a enormous impact in reducing the overall personal preference in the weight age calculation, the pair wise calculation of the upper diagonals is subjective, as an attempt to further reduce the degree of subjectivity in the decision making process, the Consistency Ration (CR) was used to instruct the decision maker is any personal preference was introduced into the selection process. In such a situation the decision maker would be advised to reevaluate the values entered previously. Monitoring of the implementation of the solution showed positive results with positive throughput efficiency as shown in Figure 8. 


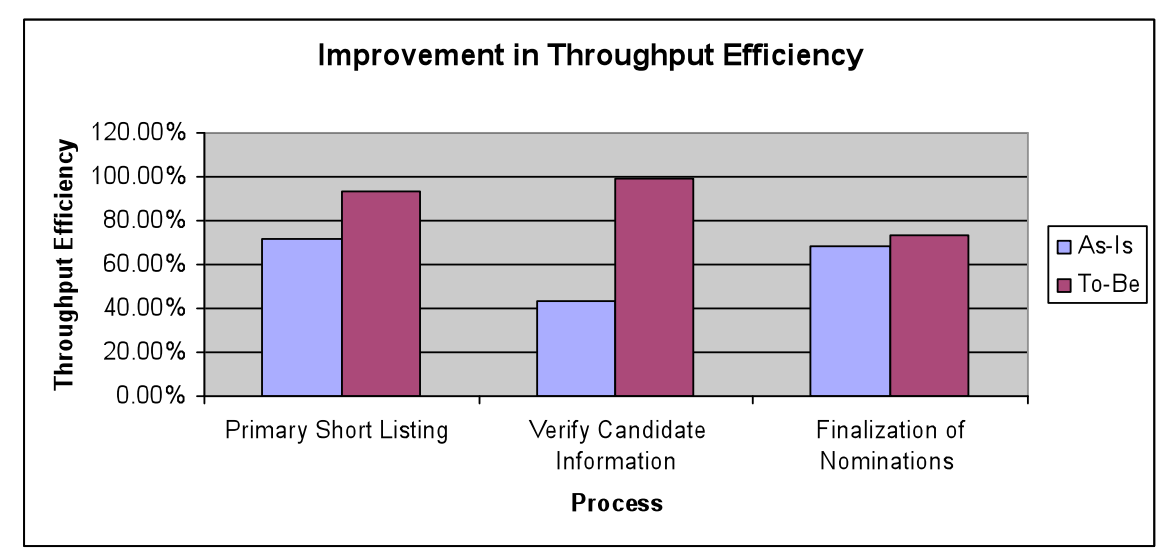

Figure 4: Throughput Efficiency Comparison

As a result of the proposed framework the throughput efficiency of the overall short listing procedure was proven to be improved by $30.14 \%$, and based on a study carried out it was also evident that it eliminates the need for manual labor by $80 \%$ and speed up the overall time by $70 \%$. Thus in conclusion the proposed solution increases the overall throughput efficiency of the candidate selection process whilst improving the quality of the overall selection.

\section{REFERENCES}

Al-Najjar \& Alsyouf (2002). Selecting The Most Efficient Maintenance Approach Using Fuzzy Multiple Criteria Decision Making. International Journal of Production Economics, Volume 84, Issue 1, 89.

Chang, Y. \& Yeh, C. (2001). Evaluating airline competitiveness using multi attribute decision making. Omega, Volume 29, Issue 5, October 2001, $405-415$.

Chien, C. \& Chen, L. (2006). Data mining to improve personnel selection and enhance human capital: A case study in high-technology industry. Expert Systems with Applications, Volume 34, Issue 1, 1

Chou, S-Y, Chang, Y-H \& Shen, C-Y. (2008). A fuzzy simple additive weighting system under group decision-making for facility location selection with objective/subjective attributes. European Journal of Operational Research, Volume 189, Issue 1, 132 - 145.

Eldrandaly , K., Eldin, N. \& Sui , D. (2002). A COM-based Spatial Decision Support System for Industrial Site Selection. Journal of Geographic Information and Decision Analysis. Vol. 7, No. 2, 1-2.

Fisher, C.D., Schoenfeldt, L.F. \& Shaw, J.B. (2003). Human Resources Management, 5th Ed. NY: Houghton Mifflin Company

Gass, S. I. (1998), Tournaments, Transitivity and Pair wise Comparison Matrices, The Journal of the Operational Research Society, Vol. 49, No. 6, 616 - 624

Leung, L.C. \& Cao, D. (2001). On the efficacy of modeling multi-attribute decision problems using AHP and Sinarchy, European Journal of Operational Research, Volume 132, Issue 1, 1. 
Mamat, N.J.Z. \& Daniel, J.K. (2007). Statistical analyses on time complexity and rank consistency between singular value decomposition and the duality approach in AHP: A case study of faculty member selection, Mathematical and Computer Modeling, Volume 46, Issues 7-8, 1099 -1106

Pomerol, J. C., \& Adam, F. (2003). From Human Decision Making to DMSS Architecture. In M. Mora, G. Forgionne, \& J. Gupta, Decision Making Support Systems: Achievements and Challenges for the New Decade (pp. 40-70). United States of America: Idea Group Publishing.

Pomerol, J. C. \& Adam, F. (2004). Practical Decision Making - from the legacy of Herbert Simon to Decision Support Systems, 649 - 653

Shih, H., Shyur, H. \& Lee, E.S. (2007). An extension of TOPSIS for group decision making, Mathematical and Computer Modeling, Volume 45, Issues 7-8, 801 - 813

Stutzke, R. D. (2007). Tools for Decision Analysis and Resolution. Science Applications International Corporation, 24.

Teknomo, K. (2006). Analytic Hierarchy Process (AHP) Tutorial, [www Page]. URL: http://people.revoledu.com/kardi/tutorial/ahp/

Turban, E., Aronson, J. E. \& Liang, T. (2005). Decision Support Systems and Intelligent Systems, 7th Ed., USA: Prentice-Hall 